
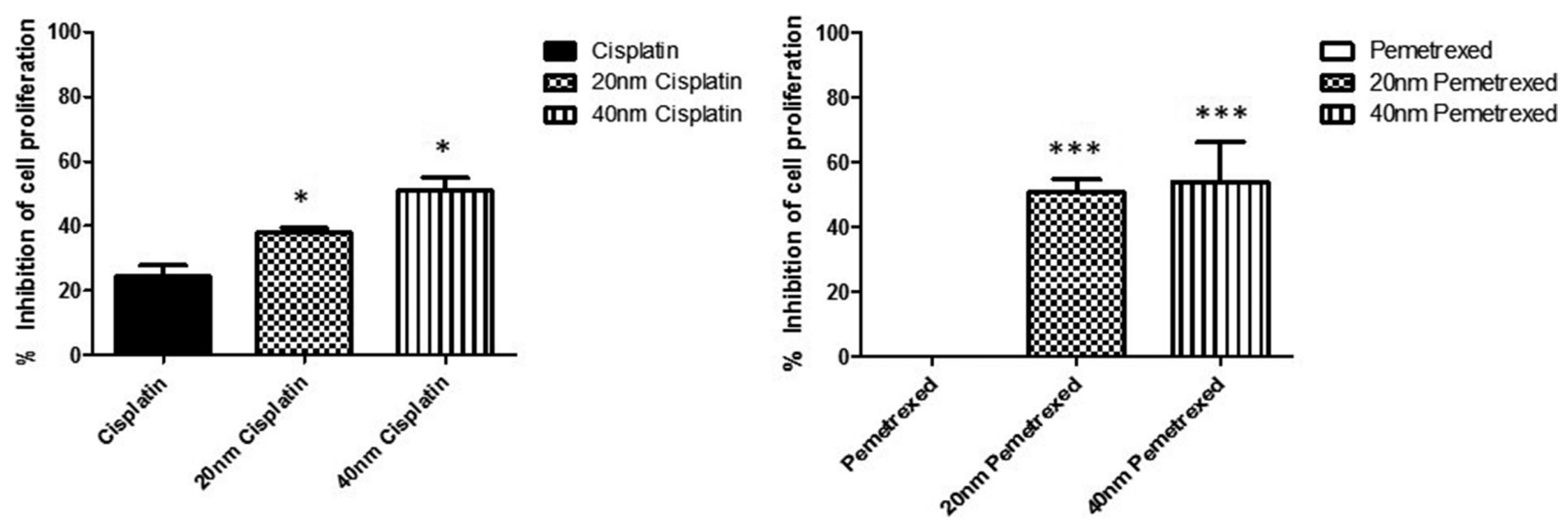

Abstract S103 Figure 1 Effect of free drug and AuNP conjugates on cancer cell proliferation. A549 cells were exposed to $10 \mu \mathrm{M}$ cisplatin (A) or pemetrexed (B) and equimolar concentrations of $20 \mathrm{~nm}$ and $40 \mathrm{~nm}$ conjugates. Proliferation was measured at 48 hours by electrical cell-substrate impedance. Data expressed as mean $\pm \mathrm{SE}(\mathrm{n}=3)$. ${ }^{*} P<0.05$ conjugate vs free cisplatin, ${ }^{* *}{ }^{*} P<0.0001$ conjugate vs free pemetrexed

Conclusions We have synthesised gold-based nanomedicines that are more efficacious and biocompatible than free drug in in vitro cell models, suggesting these formulations could have enhanced therapeutic potency and improve patient quality of life.

\section{S104 FACTORS AFFECTING SENSITISING EGFR MUTATION RATE AND CELL TYPE IN STAGE IIIB/IV LUNG CANCER}

${ }^{1}$ MPT Kennedy, ${ }^{2}$ JA Quinn, ${ }^{1}$ AR Biswas, ${ }^{1}$ A Rothwell, ${ }^{3} A$ Scally, ${ }^{2}$ L Cheyne, ${ }^{1}$ MEJ Callister. ${ }^{1}$ Leeds Teaching Hospitals NHS Trust, Leeds, UK; ${ }^{2}$ Bradford Teaching Hospitals NHS Foundation Trust, Bradford, UK; ${ }^{3}$ University of Bradford, Bradford, UK

\subsection{6/thoraxjin-2015-207770.110}

Introduction Treatments for advanced lung cancer in patients with a poor performance status are limited. Such patients (PS 34) may not be suitable for chemotherapy for NSCLC, but may benefit from chemotherapy if SCLC is confirmed or treatment with an EGFR-TKI if an EGFR sensitising mutation (EGFR-sm) is detected. Estimates of the likelihood of detecting these two subtypes will enable patients to make informed decisions about undergoing biopsy confirmation.

Aim To analyse patient factors that affect the frequency of sensitising EGFR mutations and cell types in patients with stage IIIB/ IV lung cancer.

Method Retrospective review of an electronic database of stage IIIB/IV lung cancer patients with known cell type from 20082013 where a quantified smoking history was available. Where EGFR testing was not performed, the estimated prevalence of EGFR-sm was extrapolated from those patients tested according to cell type. Patients with small cell and large cell lung cancer were presumed to be EGFR wild type.

Results 1033 were identified who fulfilled the inclusion criteria. Cell types were as follows: Adenocarcinoma 31.2\%, Squamous Cell 23.5\%, Small Cell 22.7\%, NSCLC NOS 16.2\% and Large Cell 6.4\%.

Of $348(33.7 \%)$ undergoing genetic testing, EGFR-sm were found in $39(11.2 \%)$ patients. These included 32 of 241 (13.3\%) adenocarcinoma, 6 of 80 (7.5\%) NOS and 1 of 27 $(3.7 \%)$ squamous cell. The prevalence of EGFR-sm was estimated for the 384 patients with Adenocaricinoma, NOS and Squamous Cell Carcinoma who were not tested.

Table 1 shows the effect of age and pack year smoking history on EGFR mutation status and cell type. Logistic regression analysis shows increasing pack years $(\mathrm{p}<0.001)$ and younger age $(\mathrm{p}=0.004)$ are associated with a lower rate of sensitising EGFR mutations. Increasing pack years is associated with a higher frequency of small cell cancers, but this is not affected by age.

\begin{tabular}{llll}
\multicolumn{2}{l}{ Abstract S104 Table 1} & \multicolumn{2}{c}{ Age (years) } \\
\cline { 3 - 3 } & & $<80$ & $80+$ \\
\hline Smoking (pack years) & Never & $29.1 \%$ EGFR-sm & $31.8 \%$ EGFR-sm \\
& & $1.9 \%$ SCLC & $10.0 \%$ SCLC \\
& $n=54$ & $n=2$ \\
& $<20$ & $8.4 \%$ EGFR-sm & $15.3 \%$ EGFR-sm \\
& $16.5 \%$ SCLC & $16.7 \%$ SCLC \\
& $n=91$ & $n=3$ \\
& $20+$ & $3.4 \%$ EGFR-sm & $5.4 \%$ EGFR-sm \\
& $25.9 \%$ SCLC & $21.4 \%$ SCLC \\
& $n=726$ & $n=112$ \\
\hline
\end{tabular}

Conclusion Smoking status significantly impacts the likelihood of detecting both EGFR-sm and SCLC, whereas age alters the likelihood of EGFR-sm alone. These data may allow a more informed discussion regarding the likelihood of detecting an actionable result in patients with advanced lung cancer with poor performance when discussing options for biopsy.

\section{S105 MICRODROPLET DIGITAL PCR FOR THE LONGITUDINAL MONITORING OF CIRCULATING TUMOUR DNA BIOMARKERS IN UNSELECTED PATIENTS WITH ADVANCED LUNG CANCER}

${ }^{1} \mathrm{E}$ Karampini, 'A Muhith, ' $\mathrm{H}$ Farah, ${ }^{2} \mathrm{~J}$ King, ${ }^{1} \mathrm{P}$ Cane, ${ }^{1} \mathrm{~J}$ Spicer, ' $\mathrm{F}$ McCaughan. ${ }^{1} \mathrm{King}$ 's College London, London, UK; ' 'Guy's and St Thomas NHS Trust, London, UK

\subsection{6/thoraxjnl-2015-207770.111}

Introduction and objectives Circulating cell-free tumour DNA (cfDNA) can be detected in patients with solid organ malignancies and has the potential to be used as a non-invasive biomarker. Specific mutational events can be identified in biopsies using targeted next-generation sequencing and individualised microdroplet digital PCR (mdPCR) assays designed to detect and monitor the individualised biomarker in plasma. This can inform 